\title{
Simulation results of the grasping analysis of an underactuated finger
}

\author{
Vincenzo Niola $^{1 \mathrm{a}}$, Cesare Rossi $^{1}$, Sergio Savino ${ }^{1}$ \\ ${ }^{1}$ University of Naples "Federico II" Via Claudio 21, 80125, Naples ITALY
}

\begin{abstract}
The results of a number of simulations concerning the grasping analysis is presented. The grasping device consist in an under-actuated finger driven by un-extendible tendon that is one of the fingers of a mechanical prosthesis that was principally conceived as human prosthesis. The results, however, are useful for any similar finger to be used in grasping devices for industrial and agricultural applications, Aanalysis maps of the grasping were obtained which show the "robustness" of the socket. The method seems to be a suitable tool for the optimum design of such under-actuated fingers for grasping devices.
\end{abstract}

\section{Introduction}

In the last decades, grasping devices based on the human hand were widely studied an developed (see e.g. [1-13]); this both for human prostheses and for industrial or agricultural purposes. Among these studies the authors conceived developed and patented a new mechanical hand (Federica mechanical hand) based on a self-adaptive patented scheme (patent n. 0001415546 and $n$. 102015000059873 , the latter pending) based on a selfadaptive scheme and under-actuated fingers operated by un-extendible tendons.

The main results of these investigations were reported in some papers and conference proceedings [14-18].

In figure 1 a scheme of the self-adapting system of the hand tendons and of one of the fingers are shown.

In figure 2 an hand prototype showing a correct grasping of a rather complex object by all the fingers is reported.

The study, the testing and the prototyping of the fingers and of the whole hand were presented in previous paper (see e.g. [14-18]).

Being the 3 phalanxes of the finger operated by an extension tendon and just one flexion tendon, the finger itself is underactuated, hence it becomes crucial a correct design of the phalanxes, of the tendon guide and of the hinges positions, in order to obtain a correct grasping of almost any possible object.

The grasping of an object can be very different depending on the position of the object respect to the grasping device. In the case of the single finger the figures 2 and 3 show that the quality of the grasp may be deeply different. In both the figures the grasping of a sphere is shown.

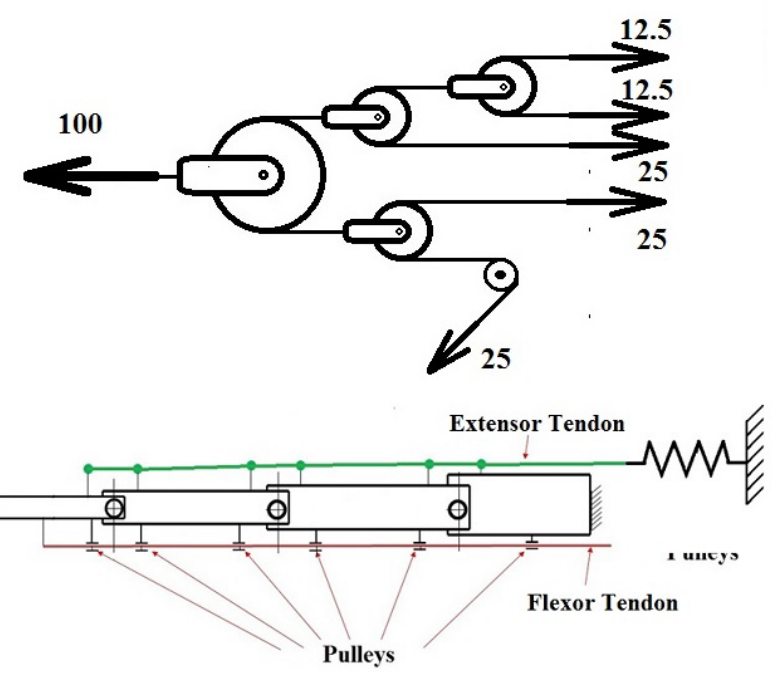

Figure 1. Schemes of the pulley system and of the finger.

In figure 3 an almost perfect grasping is shown: the inner surface of each of the phalanxes almost perfectly onto contact with the surface of the sphere. In figure 4, instead, the sphere is just roughly grasped since just the fingertip and the palm of the hand are onto contact with the surface of the sphere.

For the reasons above, it seemed to us interesting to propose and test a method to predict the grasping efficiency of each of the underactuated fingers that compose the mechanical hand we conceived.

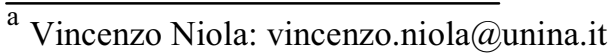


The method was presented in [19]; in the following some of the most significant results are presented.

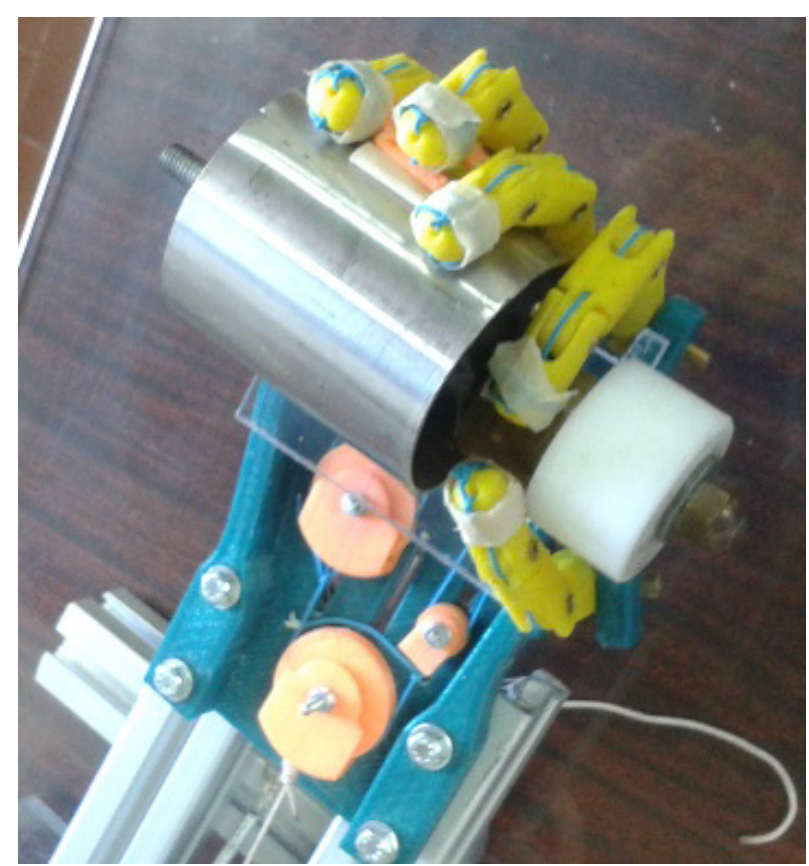

Figure 2. An hand prototype correctly grasping an object.

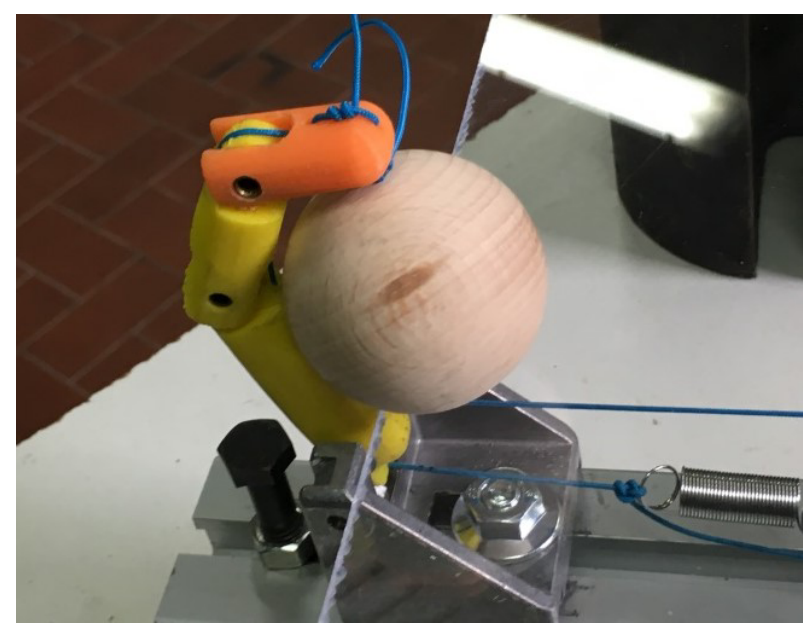

Figure 3. Good grasping of a sphere

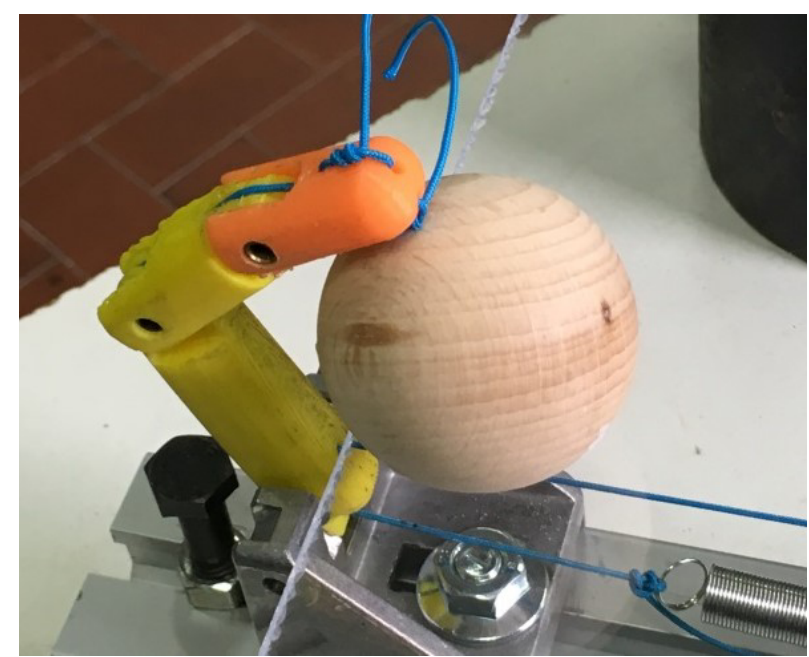

Figure 4. Instable grasping of a sphere

\section{The contact between surfaces}

The contact model was already described in [19] so we just briefly describe it.

The contact of the fingertip of each phalanx with the objects was simulated with an elastic damping reaction and a friction force between the bodies. In particular to analyze the contact of the finger with the object, each phalanx of the finger has been covered with a plain "skin", in this way the type of contact is always between a plane and a sphere. In figure 5 the model with the plain skin is shown.

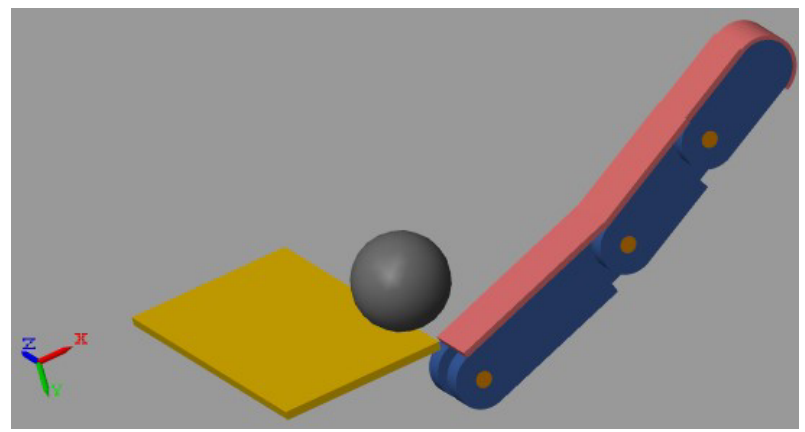

Figure 5. The multibody finger mode with plain "skin" to simulate the contact with the object.

The contact between two bodies was simulated with a force applied only along the direction of penetration of the two bodies. In figure 6 this force is shown as $F_{n}$, and it acts on the plane and on the sphere in the opposite direction.

In the contact model, also the friction force is included; it acts as a tangential force in the contact point on both bodies. In figure 6 the friction force is shown as $F_{t}$.

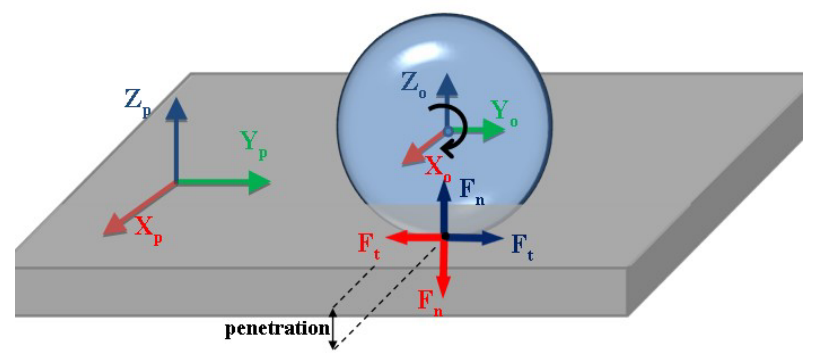

Figure 6. Contact scheme with normal force Fn and friction force $\mathrm{Ft}$.

The normal force $F_{n}$ acts by opposing the penetration of the two bodies and the damping is zero when the penetration decreases.

$\mathrm{F}_{\mathrm{n}}=\left\{\begin{array}{cc}\mathrm{k} \cdot \mathrm{Z}_{\text {penetratio }}+\mathrm{b} \cdot \mathrm{v}_{\text {penetratio }} & \forall \mathrm{Z}_{\text {penetratio }}>0, \mathrm{v}_{\text {penetratio }}>0 \\ \mathrm{k} \cdot \mathrm{Z}_{\text {penetratio }} & \forall \mathrm{Z}_{\text {penetratio }}>0, \mathrm{v}_{\text {penetratio }}<0 \\ 0 & \forall \mathrm{Z}_{\text {penetratio }}<0\end{array}\right.$ 
Where $Z_{\text {penetration }}$ is the penetration between the two bodies,$v_{\text {penetration }}$ is the velocity of penetration, $\mathrm{k}$ is the contact stiffness and $\mathrm{b}$ is the contact damping.

The friction force $F_{t}$ is the product of normal force and $a$ coefficient of friction that is a function of the relative velocity at the contact point.

$$
F_{t}=F_{n} \cdot \mu, \quad \mu=f\left(v_{C P}\right)
$$

Where $\mu$ is the coefficient of friction and $v_{C P}$ is the relative velocity at the contact point.

In particular the coefficient $\mu$ has the following expression (3).

$$
\mu=f\left(v_{C P}\right)=\left\{\begin{array}{cc}
\mathrm{v}_{\mathrm{CP}} \cdot \mu_{\mathrm{s}} / \mathrm{v}_{\text {thr }} & \mathrm{v}_{\mathrm{CP}}<\mathrm{v}_{\text {trh }} \\
\mu_{\mathrm{s}}-\mathrm{v}_{\mathrm{CP}} \frac{\mu_{\mathrm{s}}-\mu_{\mathrm{k}}}{0.5 \cdot \mathrm{v}_{\mathrm{thr}}} & \mathrm{v}_{\text {trh }} \leq \mathrm{v}_{\mathrm{CP}} \leq 1.5 \cdot \mathrm{v}_{\text {trh }} \\
\mu_{\mathrm{k}} & \mathrm{v}_{\mathrm{CP}}>1.5 \cdot \mathrm{v}_{\text {trh }}
\end{array}\right.
$$

Where $\mu_{\mathrm{s}}$ is the static friction coefficient, $\mu_{\mathrm{k}}$ is the kinetic friction coefficient and $v_{\text {thr }}$ is a velocity threshold starting from which it is necessary to use the kinetic friction coefficient.

\section{SIMULATION RESULTS}

The multibody model finger that was developed was used to analyze the grasping efficiency while the position of the object was changed. The result consists in maps in which while the position of the object is changed, the grasping quality is evaluated. In the following examples the grasped object is represented by a sphere.

The robustness of the grasp is measured by analyzing different parameters. In particular, using the model, the following parameters are analyzed:

- the object's speed respect to the phalanges,

- the velocity of the object respect to the palm,

- the object contact with the phalanges and palm.

All these parameters were used to define a function of grasping $\mathrm{G}$ described by the expression (4):

$$
G=
$$$$
\left\{\begin{array}{r}
0.50 \text { if } v_{o b j} \text { distal } \cong 0 \cup v_{o b j} \text { medial } \cong 0 \cup v_{o b j} \text { proximal } \cong 0 \\
0.75 \quad \text { if } v_{o b j} \text { palm } \cong 0 \\
1.00 \quad \text { if the object is in contact with } 2 \text { surfaces } \\
2.00 \quad \text { if the object is in contact with at least } 3 \text { surfaces }
\end{array}\right.
$$

Where:

$\mathrm{v}_{\text {obj }}$ distal, $\mathrm{v}_{\mathrm{obj}}$ medial and $\mathrm{v}_{\text {obj }}$ proximal are the velocity of the object respect to the distal, medial and proximal phalanx, respectively;

$\mathrm{v}_{\mathrm{obj}}$ palmi is the velocity of the object respect to the palm.
Naturally the function $\mathrm{G}$ also assumes composite values when more conditions simultaneously occur.

\subsection{The grasping of the sphere by the finger}

The grasping ability of a single finger of the Simulink model of Federica hand was tested; this was made both considering the object fixed and mobile. The simulations provide to move the ball in a plane orthogonal to the surface of the palm considering positions spaced of 2 $\mathrm{mm}$. In the cases analyzed the ball center is situated in correspondence of the finger. Each simulation includes an analysis of approximately 300 positions and the result returns a graphic having different colored areas, depending on the contact. In figures 7 and 8 the cases of a fixed sphere of radius $\mathrm{r}=1 \mathrm{~cm}$ and $\mathrm{r}=1,15 \mathrm{~cm}$ are reported.

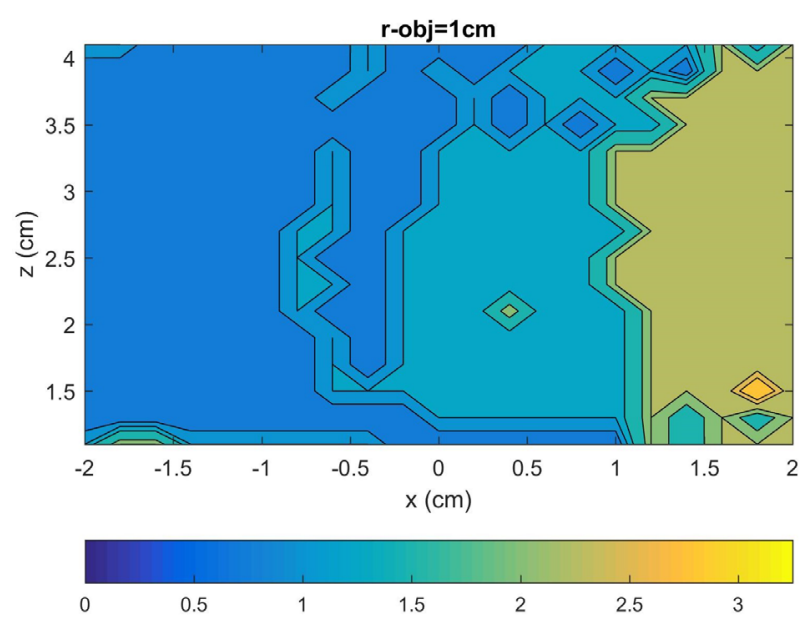

Figure 7. Results with fixed sphere of radius $1.0 \mathrm{~cm}$.

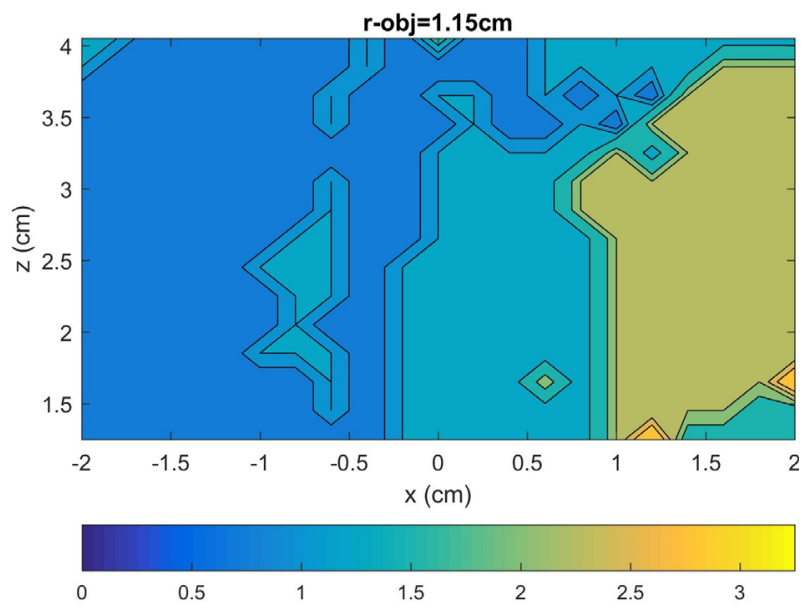

Figure 8. Results with fixed sphere of radius $1.15 \mathrm{~cm}$.

The color to yellow indicates that contact is made with at least two surfaces. We note that the objects are of similar size, but the results in term of grasping are slightly better with the largest object because the contact area is larger.

When the object is movable, the grasping takes place in different areas; it often happens that the ball is grasped with the distal phalanx while the finger is fully extended. 


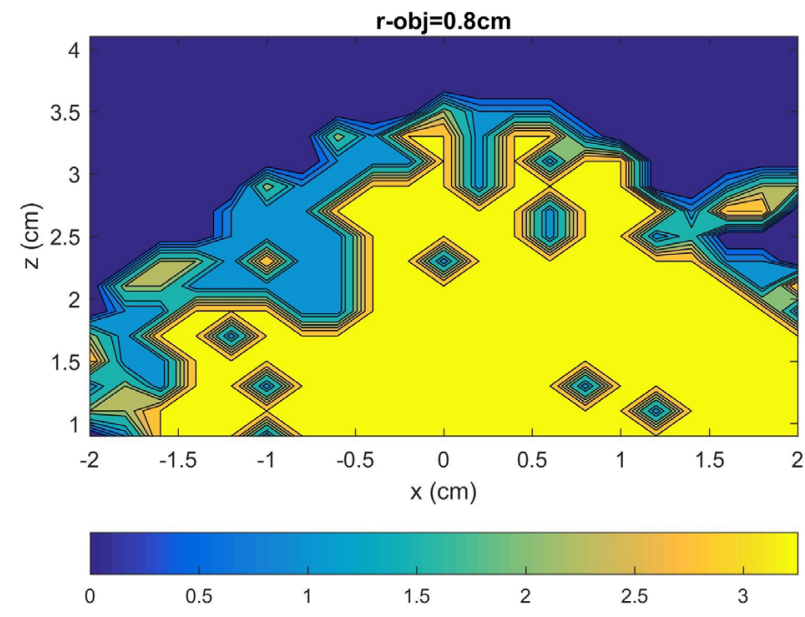

Figure 9. Results with moving sphere of radius $0.8 \mathrm{~cm}$.

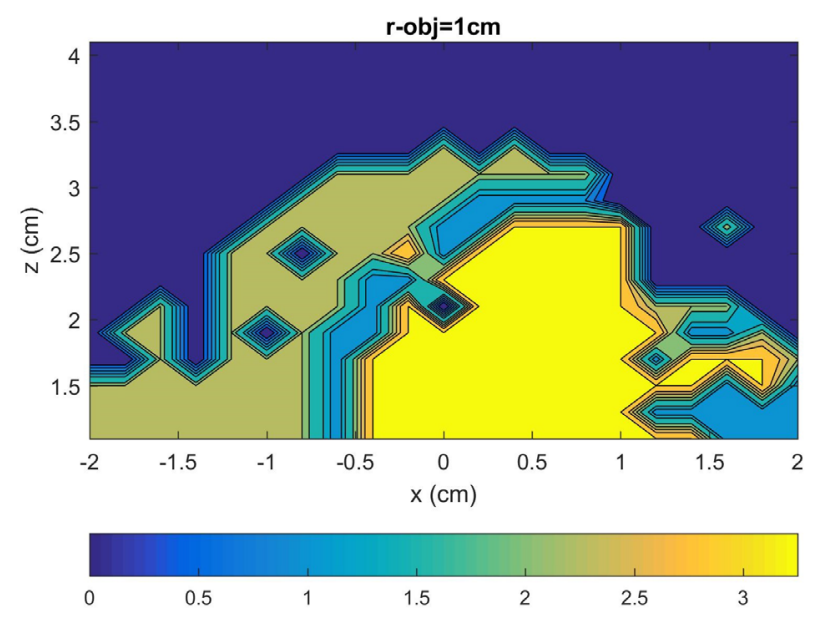

Figure 10. Results with moving sphere of radius $1.0 \mathrm{~cm}$.

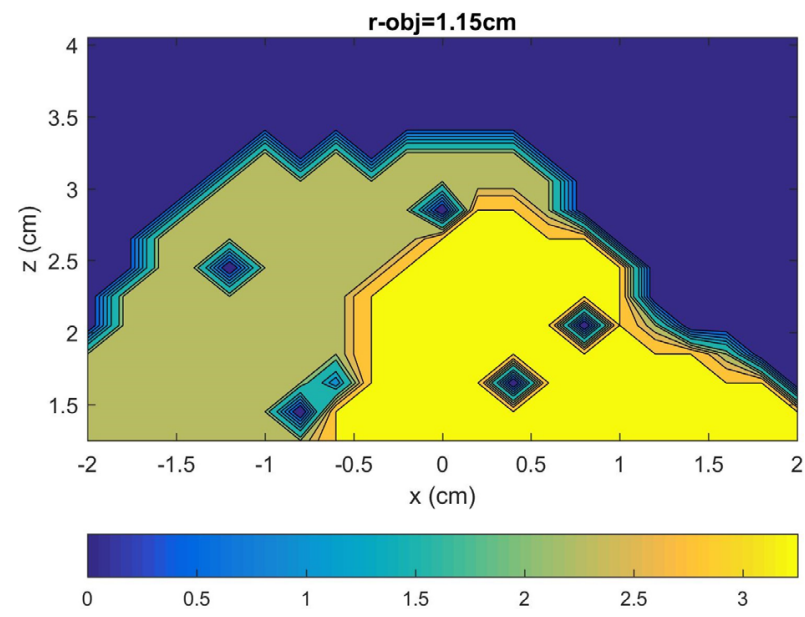

Figure 11. Results with moving sphere of radius $1.15 \mathrm{~cm}$.

In figures $9,10,11$ and 12 the cases with a ball of radius $r$ $=0.8 \mathrm{~cm}, \mathrm{r}=1 \mathrm{~cm}, \mathrm{r}=1.15 \mathrm{~cm}$, and $\mathrm{r}=1.5 \mathrm{~cm}$ are analyzed.

The higher the object's radius, the most "elusive" the grasping is; the finger often fails to stop the ball that rolls and falls from the palm of the hand. This occurrence is more evident in figure 12 , where the ball radius is $r=1.5$ $\mathrm{cm}$ and the area with a high value of $\mathrm{G}$ is very small.

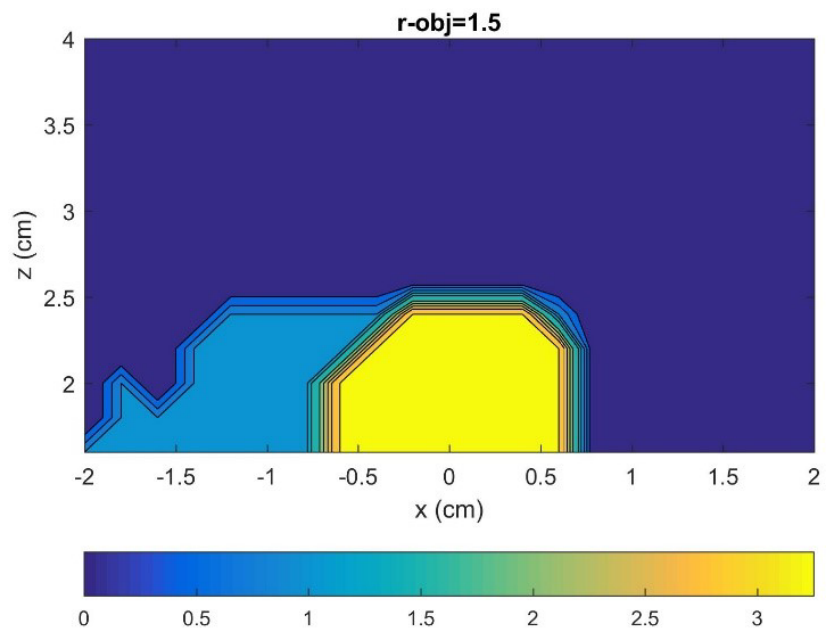

Figure 12. Results with moving sphere of radius $1.5 \mathrm{~cm}$.

\subsection{Finger with inclined surface}

In the previous model the contact surfaces of the phalanxes are flat, and they have no inclination. A further investigation was carried on by tilting the contact surfaces of an angle of $5^{\circ}$.

In particular, it must be observed that referring to the distal and medial phalanxes the tilted surface promotes the slip off of the object towards the inside part of the finger; the inclination of the proximal phalanx, instead, acts in the opposite way since it facilitates the positioning of the object towards the medial phalanx. In figure 13 the arrangement of the surfaces is shown.

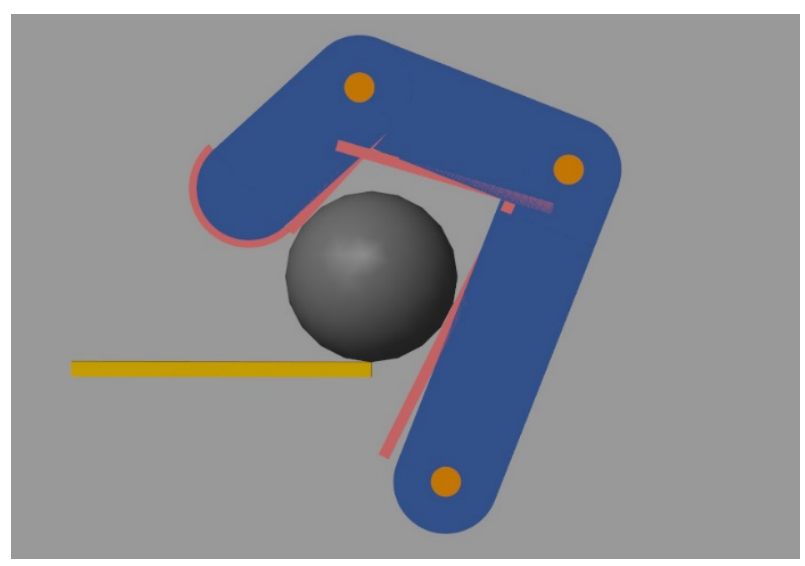

Figure 13. Finger model with inclined contact surfaces.

With this new configuration the grasping is improved especially in the case of a mobile object.

Figure 14 shows the results of the analysis with the mobile sphere of radius $\mathrm{r}=1.15 \mathrm{~cm}$, and figure 15 shows the results with a mobile sphere of radius $\mathrm{r}=1.5 \mathrm{~cm}$. 
The area where the better grasping occurs ( high values of $\mathrm{G})$ is increased respect the one referred to the case with inclined contact surfaces, figures 11 and 12 .
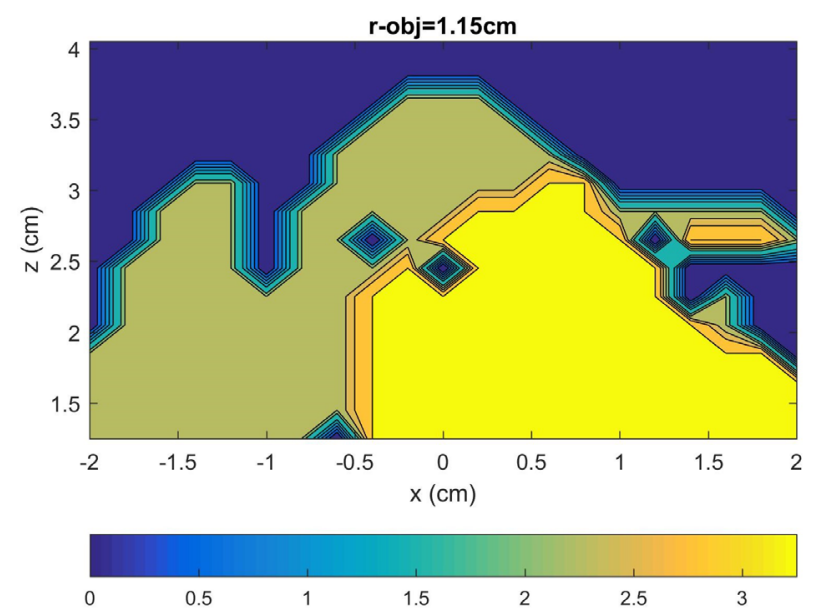

Figure 14. Results with moving ball of radius $1.15 \mathrm{~cm}$ and contact surfaces inclined.

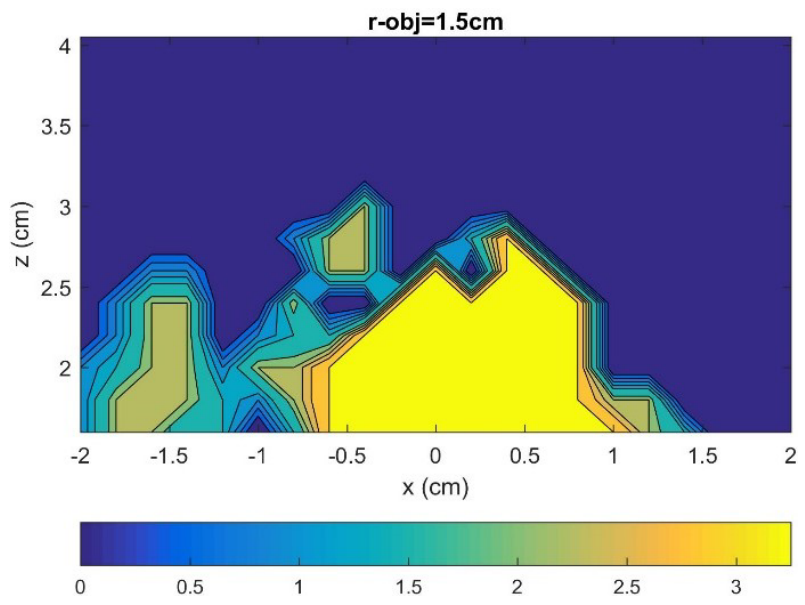

Figure 15. Results with moving ball of radius $1.5 \mathrm{~cm}$ and contact surfaces inclined.

\section{Conclusion}

The developed finger model was used to obtain analysis maps of the grasping that permit to evaluate the "robustness" of the grasping.

The reported results it appears that the proposed tool is a suitable instrument to analyze the grasping; in fact it permits to highlight the different results obtained by changing the parameters of the finger.

From the latter point of view, hence, the tool is also useful for the optimum finger design.

The next applications will concern the study of the results obtained with different contact surfaces (for example, truncated-spherical).

The dynamical behavior of the finger during the grasp can be also analyzed as function of different laws of motion, [20], of the only one actuator, by means of this model.
The finger model will then be extended to the entire hand studying the grasping quality of the whole gripping device, and comparing the virtual results relative to some points of the model with real measures acquired with vision systems, [21-24].

Finally, the proposed method is also suitable to study several different topics (even very different from this one) the authors are investigating on. Among these, even the dynamics of the throwing machines (see e.g. [25-27]), as for the impact between their component is concerned, can be studied.

\section{ACKNOWLEDGEMENT}

During this research a valuable help was provided by $\mathrm{Mr}$. Francesco Iodice who was working for the bachelor's degree. The authors thank him for his diligence and his help.

\section{References}

1. Suárez, R., Roa, M. A., \& Cornellà, J., Grasp quality measures. Technical University of Catalunya, Technical Report IOCDT-P-2006-10 (2006)

2. Roa, M. A., Suárez, R., Grasp quality measures: review and performance, Autonomous Robots, vol 38, Issue 1, pp 65-88 (2015)

3. Gabiccini, M., Farnioli, E., and Bicchi, A., Grasp and manipulation analysis for synergistic underactuated hands under general loading conditions, In International Conference of Ro-botics and Automation - ICRA 2012, pages 2836 - 2842, Saint Paul, MN, USA (2012).

4. Gabiccini, M., Farnioli, E., Bicchi, A., Grasp Analysis Tools for Synergistic Underactuated Robotic Hands. International Journal of Robotic Research, vol. 32, pp. 1553-1576 (2013)

5. Lotti, F., Vasura, G., Design aspects for advanced robot hands, In Proc. of IEEE/RSJ In-ternational Conference on Intelligent Robots and Systems, Lausanne, Switzerland, sep-tember 30 - October 4 , 2002.

6. Roccella, S., Carrozza, M.C., Cappiello, G., Dario, P., Cabibihan, J.J., Zecca, M., Miwa, H., Itoh, K., Matsumoto, M., Takanishi, A., Design, fabrication and preliminary results of a Novel anthropomorphic hand for humanoid robotics: $\mathrm{RCH}-1$, Proceedings of 2004 IEEE/RSJ International Conference on Intelligent Robots and Systems, Sendai, Japan, September 28 - October 2, 2004

7. Hirose, S., Umetani, Y, The development of soft gripper for versatile robot hand, Mechanism and Machine Theory, vol. 13, pp. 351-359 (1978)

8. Catalano M. Grioli, G., Serio, A. , Farnioli, E., Piazza, C. and Bicchi, A., Adaptive Synergies for a Humanoid Robot Hand. In Proc. of IEEE-RAS International Conference on Humanoid Robots, Osaka (Japan), October 2012 
9. Townsend, W., The BarretHand grasper programmably flexible part handling and assem-bly, Industrial Robot: An International Journal, vol.27, no. 3, pp. 181-188 (2000)

10. Baril M., Laliberte T., Gosselin C., Routhier F., On the Design of a Mechanically Programmable Underactuated Anthropo-morphic Prosthetic Gripper. Journal of Mechanical Design, issue 135, vol 12, doi:10.1115/1.4025493 (2013)

11. Dechev N., Cleghorn, W.L., Naumann, S., Multiple finger, passive adaptive grasp prosthetic hand, Mechanism and Machine Theory, vol. 36, pp 11571173 (2001)

12. Gosselin C., Pelletier, F., and Lalibertè, T. An Anthropomorphic Underactuated Robotic Hand with 15 Dofs and a Single Actuator. In Proc. of 2008 IEEE International Conference on Robotics and Automation, Pasadena (CA, USA), May 19-23 (2008)

13. Groenewegen, M. W., Aguirre, M. E., \& Herder, J. L., Design of a Partially Compliant, Three-Phalanx Underactuated Prosthetic Finger. In ASME 2015 International Design Engineering Technical Conferences and Computers and Information in Engineering Conference American Society of Mechanical Engineers (2015)

14. Rossi, C., Savino, S., Mechanical Model of a Single Tendon Finger, Proc. of ICNAAM 2013: 11th International Conference of Numerical Analysis and Applied Mathematics, Rhodes, Greece, Sep 21-27 (2013)

15. Penta, F., Rossi, C., Savino, S., An Underactuated Finger for a Robotic Hand. International Journal of Mechanics and Control, Vol. 15, n.2, ISSN: 15908844 (2014)

16. Niola, V., Rossi, C., Savino, S. (2014). "A new mechanical hand: Theoretical studies and first prototyping", International Review of Mechanical Engineering, volume 8, issue 5, pp. 835-844, ISSN:19708734.

17. Niola, V., Penta, F., Rossi, C., Savino, S., An underactuated mechanical hand: Theoretical studies and prototyping, International Journal of Mechanics and Control, Volume 16, Issue 1, pp. 11-19 (2015)

18. Carbone G., Rossi C., Savino S., (2015). "Performance comparison between Federica Hand and LARM Hand", International Journal of Advanced Robotic Systems, 14 July 2015, Volume 12, DOI: 10.5772/60523, ISSN: 17298806

19. Rossi, C., Savino, S., Timpone, F., Multibody model for evaluate quality grasping of an underactuated mechanical finger, Proc. of RAAD 2016, 30 June-2 July, 2016, Belgrade.

20. Niola, V., Rossi, C., Savino, S. and Strano, S., Robot trajectory planning by points and tan-gents. In Proceedings of the 10th WSEAS International Conference on Robotics, Control and Manufacturing Technology, ROCOM '10, Hangzhou, China, April 11-13, 2010, pp-91-96 (2010)

21. V. Niola, C. Rossi, S. Savino - "A New Real Time Shape Acquisition with a Laser Scanner: First Test Results" - ROBOTICS AND COMPUTER-
INTEGRATED MANUFACTURING, issue 6, vol. 26, December 2010, pp 543-550, ISSN 0736-5845.

22. V. Niola, C. Rossi, Video acquisition of a robot arm trajectories in the work space, WSEAS Transactions on Computers, vol. 4, issue 7, pp. 830-836, (2005)

23. Niola, V., Quaremba, G., Amoresano, A., A study on infrared thermography processed trough the wavelet transform, Proceedings of the 8th WSEAS International Conference on System Science and Simulation in Engineering, ICOSSSE '09, pp 57-62 (2009)

24. M. Martorelli, C. Rossi, S. Savino, G. Staiano (2015) A Contactless Robot Kinematic Calibration Method by Digital Photogrammetry. International Journal of Mechanics and Control (JoMaC) vol. 16, No.2, ISSN: 1590-8844.

25. Rossi, C. Ancient throwing machines: A method to calculate their performance 2012. Mechanism and Machine Theory.

26. Rossi, C., Russo, F., A reconstruction of the GreekRoman repeating catapult, Mechanism and Machine Theory, Volume 45, Issue 1, pp 36-45 (2010)

27. Rossi, C., Pagano, S., A study on possible motors for siege towers, Journal of Mechanical Design, Transactions of the ASME, Volume 133, Issue 7, Article number 071009 (2011) 